\title{
The effect of nonlinear terms in boundary perturbation method on stress concentration near the nanopatterned bimaterial interface*
}

\author{
G. M. Shuvalov, A. B. Vakaeva, D. A. Shamsutdinov, S. A. Kostyrko
}

St. Petersburg State University, 7-9, Universitetskaya nab., St. Petersburg, 199034, Russian Federation

For citation: Shuvalov G. M., Vakaeva A. B., Shamsutdinov D. A., Kostyrko S. A. The effect of nonlinear terms in boundary perturbation method on stress concentration near the nanopatterned bimaterial interface. Vestnik of Saint Petersburg University. Applied Mathematics. Computer Science. Control Processes, 2020, vol. 16, iss. 2, pp. 165-176.

https://doi.org/10.21638/11701/spbu10.2020.208

Based on the Gurtin-Murdoch surface/interface elasticity theory, the article investigates the effect of nonlinear terms in the boundary perturbation method on stress concentration near the curvilinear bimaterial interface taking into account plane strain conditions. The authors consider the $2 \mathrm{D}$ boundary value problem for the infinite two-component plane under uniaxial tension. The interface domain is assumed to be a negligibly thin layer with the elastic properties differing from those of the bulk materials. Using the boundary perturbation method, the authors determined a semi-analytical solution taking into account non-linear approximations. In order to verify this solution, the corresponding boundary value problem was solved using the finite element method where the interface layer is modelled by the truss elements. It was shown that the effect of the amplitude-to-wavelength ratio of surface undulation on the stress concentration is nonlinear. This should be taken into account even for small perturbations. It was also found that the convergence rate of the derived solution increases with an increase in the relative stiffness coefficient of the bimaterial system and, conversely, decreases with an increase of the amplitude-to-wavelength ratio.

Keywords: bimaterial composites, nanomaterials, interface stress, 2D problem, boundary perturbation method, finite element method, size-effect, interface nano-asperities.

Introduction. The formation of the geometrical patterns in the interface region of the bimaterial systems is a well-known phenomena [1-3]. Various modern manufacturing techniques allow to accurately control the morphological surface modifications at the micro- and nanoscale [4, 5]. In many applications, a material design lets to achieve the improvements in mechanical, optical and electronic properties of products. However, due to the mismatch of thermal and mechanical properties in the dissimilar materials of heterostructures, stress concentrations appear near the rough interface. Variations in working or environment temperature may generally increase the stress level, which would result in microcracks nucleation and delamination in the stress concentration regions. Therefore, it is very essential for failure prediction to accurately define stress distribution along the curved interfaces.

In past decades, a number of studies have been conducted, where the stress concentration caused by surface or interface irregularities was considered [6-14]. But these studies have been focused on the case of macroscale roughness and didn't take into account the surface/interface stress, assuming it insignificant compared to the external loading. However, both experimental and theoretical results demonstrate that surface

* This work was supported by the Russian Science Foundation (project N 19-71-00062).

(C) Санкт-Петербургский государственный университет, 2020 
effects become important in mechanical and physical behavior of solids at the nanoscale. It was observed that at the nanoscale material properties depend on a specimen size. In particular, Cammarata and Sieradzki theoretically predicted effective elastic modulus enhancement/reduction of $20 \%$, when the thickness of the film reduces to below $5 \mathrm{~nm}$ [15]. Fartash et al. confirmed this result by the experiments for several multilayered metal films [16]. In studies of Sun and Zhang, it was demonstrated by atomistic simulation that the values of elastic constants of thin films are thickness dependent and approach those of the bulk as the film thickness increases [17].

In order to understand the size dependency of mechanical properties at the nanoscale, Gurtin and Murdoch developed the surface elasticity theory by modelling the surface phase as two dimensional membrane with elastic moduli differing from those of the bulk material $[18,19]$. As a result, the stress-strain constitutive equations for the surface region were formulated. The conditions of mechanical equilibrium for solid surface were described by the generalized Young-Laplace equation yielding to non-classical boundary conditions. Recently, the Gurtin-Murdoch model has been applied to formulation of boundary value problems (BVP) for nanosized structures [20-28]. The general mathematical investigation of BVP in the linear elasticity with surface stresses is presented in the work of Altenbach et al. [29]. The Gurtin-Murdoch theory was generalized by Steigmann and Ogden [30, 31 incorporating the effect of surface bending stiffness and was used in [32, 33]. It should be pointed out that a few more models can be found in the relevant literature considering the effect of surface/interface elasticity in solids [34, 35].

It is worth noting that most of the previous studies have been focused on the structural elements with defect-free surfaces and interfaces despite the fact that the perfectly flat surfaces in solids at the nanoscale is just a hypothetical situation [5]. In [36-38], the analysis of the effective elastic properties of solids with nanoscale surface roughness was performed. However, as it was mentioned above, it is very important to analyze the stress state around the surface topological defects to predict the material failure. For this purpose, the boundary perturbation method (BPM) has been used extensively [3941]. It should be noted that only the linear approximation of the BPM was analysed in these works. Considering the problem of interfacial stresses in bimaterial composites with nanosized relief, Vakaeva et al. showed that the convergence of linear BPM become worse with the increasing of amplitude-to-wavelength ratio [42]. Motivated by these results, we decided to study the effect of nonlinear terms in BPM on the stress concentration near the nanopatterned bimaterial interface.

Problem formulation. We consider the 2D problem for an elastic isotropic bimaterial with slightly perturbated interface under the uniaxial tension (Figure 1). The elastic properties of the interface differ from those of the bulk materials. In according to simplified Gurtin-Murdoch model of surface/interface elasticity [18, 19], it is represented as a negligibly thin layer $\Gamma$ coherently bonded to the bulk phases $B_{1}$ and $B_{2}$ without slipping:

$$
\begin{gathered}
\Gamma=\left\{z: z \equiv \zeta=x_{1}+i \varepsilon f\left(x_{1}\right)\right\}, \quad B_{1}=\left\{z: x_{2}>\varepsilon f\left(x_{1}\right)\right\}, \\
B_{2}=\left\{z: x_{2}<\varepsilon f\left(x_{1}\right)\right\}, \quad f\left(x_{1}\right)=-a \cos \left(b x_{1}\right),
\end{gathered}
$$

where $a$ is the perturbation wavelength; $b=2 \pi / a$ is the wavenumber; $\varepsilon=A / a$ is the amplitude-to-wavelength ratio which we consider as a small parameter, i. e. $0<\varepsilon \ll 1$, and $z=x_{1}+i x_{2}$ is a complex variable where $\left(\left(x_{1}, x_{2}\right)\right.$ are the Cartesian coordinates and $\left.i^{2}=-1\right)$. 


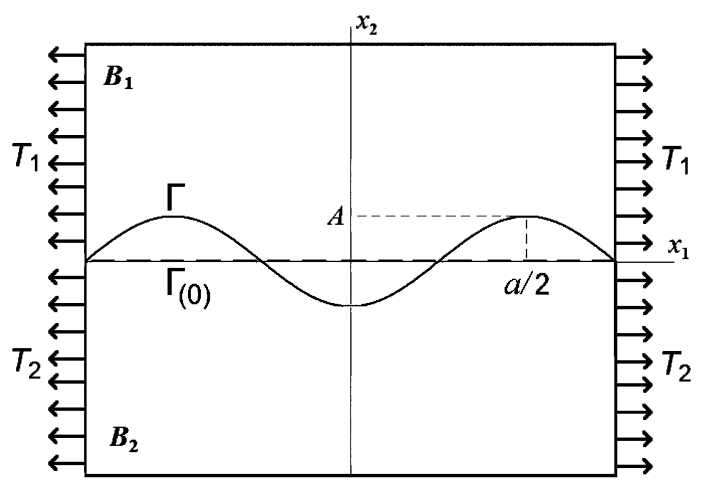

Fig. 1. A model of bimaterial with slightly perturbated interface under the uniaxial tension

To describe the elastic behavior of the interface domain we use the simplified constitutive equations of Gurtin-Murdoch model neglecting the effect of residual interface stress $[18,19]$. Due to the plane strain conditions, we derive the following scalar form:

$$
\tau(\zeta)=\sigma_{t t}^{s}=M_{s} \varepsilon_{t t}^{s}(\zeta), \quad M_{s}=\lambda_{s}+2 \mu_{s}, \quad \zeta \in \Gamma,
$$

here $\varepsilon_{t t}^{s}$ and $\sigma_{t t}^{s}$ are the nonvanishing components of the interface strain and the first Piola-Kirchhoff interface stress tensor, respectively; $\lambda_{s}$ and $\mu_{s}$ are the interface Lamé constants.

Hooke's law for bulk materials in the case of plane strain can be written as

$$
\begin{gathered}
\sigma_{n n}(z)=\left(\lambda_{j}+2 \mu_{j}\right) \varepsilon_{n n}(z)+\lambda_{j} \varepsilon_{t t}(z), \quad \sigma_{t t}(z)=\left(\lambda_{j}+2 \mu_{j}\right) \varepsilon_{t t}(z)+\lambda_{j} \varepsilon_{n n}(z), \\
\sigma_{n t}(z)=2 \mu_{j} \varepsilon_{n t}(z), \quad z \in B_{j}, \quad j=\{1,2\},
\end{gathered}
$$

where $\sigma_{n n}, \sigma_{t t}, \sigma_{n t}$ and $\varepsilon_{n n}, \varepsilon_{t t}, \varepsilon_{n t}$ are the components of bulk stress and strain tensors, respectively, defined in the local Cartesian coordinates $(n, t)$ (vectors $\mathbf{n}$ and $\mathbf{t}$ are the normal and tangential to the interface $\Gamma), \lambda_{j}$ and $\mu_{j}$ are the Lamé constants for the bulk phase $B_{j}$.

Since we assumed that the interphase layer and the bulk materials are coherent, the complex displacement vector is continuous at the interface:

$$
\Delta u(\zeta)=u^{+}(\zeta)-u^{-}(\zeta)=0, \quad \zeta \in \Gamma,
$$

here $u^{ \pm}=\lim _{z \rightarrow \zeta \pm i 0} u(z), u(z)=u_{1}(z)+i u_{2}(z), u_{1}$ and $u_{2}$ are the displacements along axes of the Cartesian coordinates $\left(x_{1}, x_{2}\right)$.

In the case of the simplified Gurtin-Murdoch model, the kinematic boundary condition is formulated on the basis of generalized Young-Laplace law:

$$
\Delta \sigma_{n}(\zeta)=\sigma_{n}^{+}(\zeta)-\sigma_{n}^{-}(\zeta)=-\kappa \tau+i \frac{1}{h} \frac{d \tau(\zeta)}{d x_{1}}, \quad \zeta \in \Gamma
$$

where $\sigma_{n}^{ \pm}=\lim _{z \rightarrow \zeta \pm i 0} \sigma_{n}(z), \sigma_{n}(z)=\sigma_{n n}(z)+i \sigma_{n t}(z), \kappa$ and $h$ are the curvature and metric coefficient of the interface $\Gamma$, respectively. 
At infinity, the stresses $\sigma_{\alpha \beta}(\alpha \beta=\{1,2\})$ in coordinates $\left(x_{1}, x_{2}\right)$ and the rotation angle $\omega$ are specified as

$$
\lim _{x_{2} \rightarrow \pm \infty} \sigma_{22}=\lim _{x_{2} \rightarrow \pm \infty} \sigma_{12}=\lim _{x_{2} \rightarrow \pm \infty} \omega=0, \quad \lim _{x_{2} \rightarrow \pm \infty} \sigma_{11}=T_{j}, \quad j=\{1,2\} .
$$

Boundary perturbation approach. According to [40], the solution of the BVP (1)-(6), specifically the stress $\sigma_{n}$ and displacement $u$ complex vectors, can be derived using Goursat-Kolosov complex potentials $\Phi_{j}$ and $\Upsilon_{j}$ :

$$
G\left(z, \eta_{j}\right)=\eta_{j} \Phi_{j}(z)+\overline{\Phi_{j}(z)}-\left(\Upsilon_{j}(\bar{z})+\overline{\Phi_{j}(z)}-(z-\bar{z}) \overline{\Phi_{j}^{\prime}(z)}\right) e^{-2 i \alpha}, z \in B_{j}, j=\{1,2\},
$$

where $\alpha$ is the angle between axis $t$ - and $x_{1}$-axis, the prime denotes differentiation with respect to the argument. The functions $\Phi_{j}, \Upsilon_{1}$ and $\Upsilon_{2}$ are holomorphic in the regions $B_{j}$ $\widetilde{B_{1}}=\left\{z: x_{2}>-\varepsilon f\left(x_{1}\right)\right\}$ and $\widetilde{B_{2}}=\left\{z: x_{2}<-\varepsilon f\left(x_{1}\right)\right\}$, respectively.

The function $G$ is defined as follows:

$$
G\left(z, \eta_{j}\right)=\left\{\begin{aligned}
\sigma_{n}, & \eta_{j}=1, \\
-2 \mu_{j} \frac{d u}{d z}, & \eta_{j}=-\varkappa_{j},
\end{aligned}\right.
$$

here $\varkappa_{j}=3-4 \nu_{j}$ and $\nu_{j}$ is the Poisson's ratio for elastic domain $B_{j}$.

Substituting (7) into boundary conditions (4) and (5), we rewrite these equations in the terms of complex potentials $\Phi_{j}$ and $\Upsilon_{j}$. The main issue here is to express explicitly the complex potentials in terms of interface stress $\tau$. It is easy to obtain such expressions in the case of the planar boundary [43]. However, it is impossible to do this in the case of curved boundary as $\zeta \neq \bar{\zeta}$. For this purpose, we use the BPM which has been applied recently in several publications to simplify BVP problems associated with complicated geometry and allowed to derive the analytic approximations of considered solutions [7-11, 39-41].

Employing BPM, we expand the functions $\Phi_{j}, \Upsilon_{j}$, and $\tau$ in power series in small parameter $\varepsilon$ as it was done in [40]:

$$
\Phi_{j}(z)=\sum_{m=0}^{\infty} \frac{\varepsilon^{m}}{m !} \Phi_{j(m)}(z), \Upsilon_{j}(z)=\sum_{m=0}^{\infty} \frac{\varepsilon^{m}}{m !} \Upsilon_{j(m)}(z), \tau(\zeta)=\sum_{m=0}^{\infty} \frac{\varepsilon^{m}}{m !} \tau_{(m)}(\zeta), j=\{1,2\} .
$$

In addition, each function $\tau_{(m)}$, and boundary values of functions $\Phi_{j(m)}$ and $\Upsilon_{j(m)}$ are represented in Taylor series in the vicinity of line $x_{2}=0$, considering $x_{1}$ as a parameter:

$$
\begin{gathered}
\Phi_{j(m)}(\zeta)=\sum_{k=0}^{\infty} \frac{\left[i \varepsilon f\left(x_{1}\right)\right]^{k}}{k !} \Phi_{j(m)}^{(k)}\left(x_{1}\right), \quad \Upsilon_{j(m)}(\bar{\zeta})=\sum_{k=0}^{\infty} \frac{\left[-i \varepsilon f\left(x_{1}\right)\right]^{k}}{k !} \Upsilon_{j(m)}^{(k)}\left(x_{1}\right), \\
\tau_{(m)}(\zeta)=\sum_{k=0}^{\infty} \frac{\left[i \varepsilon f\left(x_{1}\right)\right]^{k}}{k !} \tau_{(m)}^{(k)}\left(x_{1}\right), \quad j=\{1,2\} .
\end{gathered}
$$


Also one can write the power series for known functions:

$$
\begin{gathered}
e^{-2 i \alpha_{0}}=1+2 \sum_{m=0}^{\infty}\left(-i \varepsilon f^{\prime}\left(x_{1}\right)\right)^{m+1}, \\
\kappa\left(x_{1}\right)=\varepsilon f^{\prime \prime}\left(x_{1}\right)\left[1+\sum_{m=1}^{\infty} \frac{(-1)^{m}}{m !} \frac{(2 m-1) ! !}{2^{m}}\left(\varepsilon f^{\prime}\left(x_{1}\right)\right)^{2 m}\right], \\
h^{-1}\left(x_{1}\right)=\sum_{m=0}^{\infty} \frac{(-1)^{m}}{m !} \frac{(2 m+1) ! !}{2^{m}}\left(\varepsilon f^{\prime}\left(x_{1}\right)\right)^{2 m} .
\end{gathered}
$$

After substitution (9)-(11) into boundary conditions, which were previously written in the terms of the complex potentials on the basis of equation (7), and equating the coefficients of $\varepsilon^{m}, m=\{0,1, \ldots\}$, we derive two recurrent sequences of boundary equations associated already with the flat boundary $\Gamma_{(0)}=\left\{z: z=x_{1}\right\}$. From these equations, we obtain the integral dependencies of functions $\Phi_{j(m)}$ and $\Upsilon_{j(m)}$ on $\tau_{(m)}^{\prime}$ using the solution of Riemann-Hilbert problem:

$$
\begin{aligned}
& \begin{cases}\Phi_{1(m)}(z)=-\Upsilon_{2(m)}(z)+\Sigma_{m}(z)+O_{m}^{1}, & \operatorname{Im} z>0, \\
\Upsilon_{1(m)}(z)=-\Phi_{2(m)}(z)+\Sigma_{m}(z)+O_{m}^{1}, & \operatorname{Im} z<0,\end{cases} \\
& \begin{cases}\Upsilon_{2(m)}(z)=\frac{\mu_{2} \varkappa_{1} \Sigma_{m}(z)+V_{m}(z)}{\mu_{1}+\mu_{2} \varkappa_{1}}+O_{m}^{2}, & \operatorname{Im} z>0, \\
\Phi_{2(m)}(z)=\frac{\mu_{2} \Sigma_{m}(z)-V_{m}(z)}{\mu_{2}+\mu_{1} \varkappa_{2}}+O_{m}^{2}, & \operatorname{Im} z<0 .\end{cases}
\end{aligned}
$$

In equations (12)

$$
\begin{gathered}
\Sigma_{m}(z)=\frac{1}{2 \pi i} \int_{-\infty}^{\infty} \frac{i \tau_{(m)}^{\prime}(t)}{z-t} d t+\frac{1}{2 \pi i} \int_{-\infty}^{\infty} \frac{H_{m}^{1}(t)+Z_{m}^{k n}(t)}{z-t} d t, V_{m}(z)=\frac{1}{2 \pi i} \int_{-\infty}^{\infty} \frac{H_{m}^{2}(t)}{z-t} d t \\
H_{m}^{1}=H_{m}, \text { when } m_{k}=\eta_{k}=1, \\
H_{m}^{2}=H_{m}, \text { when } m_{k}=\mu_{k}, \eta_{k}=\varkappa_{k}, \\
O_{0}^{j}=T_{j} / 4, O_{n}^{j}=0, j, k=\{1,2\}, j \neq k, m=\{1,2, \ldots\} \\
H_{m}\left(x_{1}\right)=-\sum_{l=0}^{m-1} \frac{m !}{l !}\left\{\frac { ( i f ( x _ { 1 } ) ) ^ { k } } { k ! } \left[(-1)^{k}\left(m_{1} \Upsilon_{2(l)}^{(k)}\left(x_{1}\right)-m_{2} \Upsilon_{1(l)}^{(k)}\left(x_{1}\right)\right)+\right.\right. \\
\left.+m_{2} \eta_{1} \Phi_{1(l)}^{(k)}\left(x_{1}\right)-m_{1} \eta_{2} \Phi_{2(l)}^{(k)}\left(x_{1}\right)-2(-1)^{k-1} k\left(m_{1} \overline{\Phi_{2(l)}^{(k)}\left(x_{1}\right)}-m_{2} \Phi_{1(l)}^{(k)}\left(x_{1}\right)\right)\right]- \\
-2(-1)^{k-1} \sum_{j=1}^{k} \frac{\left(i f\left(x_{1}\right)\right)^{k-j}}{(k-j) !}\left(i f^{\prime}\left(x_{1}\right)\right)^{j}\left[m_{1} \Upsilon_{2 m}^{(k-j)}\left(x_{1}\right)-m_{2} \Upsilon_{1 m}^{(k-j)}\left(x_{1}\right)+\right. \\
\left.\left.+(2 k-2 j+1)\left(m_{1} \overline{\Phi_{2(l)}^{(k-j)}\left(x_{1}\right)}-m_{2} \overline{\Phi_{1(l)}^{(k-j)}\left(x_{1}\right)}\right)\right]\right\}
\end{gathered}
$$




$$
\begin{gathered}
Z_{m}\left(x_{1}\right)=-i \tau_{(m)}^{\prime}\left(x_{1}\right)-Z_{m}^{k n}\left(x_{1}\right), \text { when } m_{p}=\eta_{p}=1, \\
Z_{m}\left(x_{1}\right)=0, \text { when } m_{p}=\mu_{p}, \eta_{p}=\varkappa_{p}, p=\{1,2\}, \\
Z_{0}^{k n}\left(x_{1}\right)=0, \\
Z_{m}^{k n}\left(x_{1}\right)=-\sum_{l=0}^{m} \frac{m !}{l ! k !}\left(C_{m}^{1}\left(x_{1}\right) R_{j}\left(x_{1}\right)-i C_{m}^{2}\left(x_{1}\right) Q_{j}\left(x_{1}\right)\right), \quad m=\{1,2, \ldots\}, k=m-l, \\
C_{q}^{1}\left(x_{1}\right)=\sum_{q=1}^{1} \frac{l !\left(x_{1}\right)=\tau_{(0)}\left(x_{1}\right), C_{0}^{2}\left(x_{1}\right)=\tau_{(0)}^{\prime}\left(x_{1}\right),}{q !(l-q) !} \tau_{l-q}^{(q)}\left(x_{1}\right), C_{l}^{2}\left(x_{1}\right)=\sum_{q=1}^{l} \frac{l !\left(i f\left(x_{1}\right)\right)^{q}}{q !(l-q) !} \tau_{l-q}^{(q+1)}\left(x_{1}\right), \\
R_{2 q+1}=\frac{(-1)^{q}(2 q+1) !(2 q+1) ! !}{q ! 2^{q}}\left(f^{\prime}\left(x_{1}\right)\right)^{2 q} f^{\prime \prime}\left(x_{1}\right), R_{2 q}=0, \\
q ! 2^{q} \\
Q_{0}=1, H_{2 q}\left(x_{1}\right)=\frac{(-1)^{q}(2 q) !(2 q-1) ! !}{\left(f^{\prime}\left(x_{1}\right)\right)^{2 q}, Q_{2 q+1}=0, q=\{1,2, \ldots\} .}
\end{gathered}
$$

Finally, taking into account the procedure developed in [40], we come to the recurrent sequence of hypersingular integral equations in unknown functions $\tau_{(m)}^{\prime}$ :

$$
\left.\begin{array}{c}
\tau_{(m)}^{\prime}\left(x_{1}\right)-\frac{M_{s} K}{4 \mu_{2} \pi} \int_{-\infty}^{+\infty} \frac{\tau_{(m)}^{\prime}(\xi)}{\left(\xi-x_{1}\right)^{2}} d \xi=F_{m}\left(x_{1}\right), \quad m=0,1, \ldots, \\
F_{m}\left(x_{1}\right)=\frac{M_{s}}{2 \mu_{2}} \operatorname{Re}\left[\frac{K_{2}}{2}\left(H_{m}^{1 \prime}\left(x_{1}\right)+Z_{m}^{k n \prime}\left(x_{1}\right)\right)+\frac{K_{1}}{2 \pi i} \int_{-\infty}^{\infty} \frac{H_{m}^{1}(t)+Z_{m}^{k n}(t)}{(z-t)^{2}} d t+\right. \\
\left.+\frac{K_{3}}{2} H_{m}^{2 \prime}\left(x_{1}\right)+\frac{K_{4}}{2 \pi i} \int_{-\infty}^{\infty} \frac{H_{m}^{2}(t)}{(z-t)^{2}} d t\right]+W_{m}^{\prime}\left(x_{1}\right), \\
+W_{m}\left(x_{1}\right)=\frac{M_{s}}{2 \mu_{2}} \operatorname{Re}\left\{\sum _ { l = 0 } ^ { m - 1 } \frac { m ! } { l ! } \left[\frac{\left(i f\left(x_{1}\right)\right)^{k}}{k !}\left(x_{1}\right)=0, \Phi_{2(l)}^{(k)}\left(x_{1}\right)+\right.\right. \\
+m ! \sum_{l=0} \frac{(-1)^{k} f^{2 k}\left(x_{1}\right)}{l !(2 k) !} \tau_{(l)}^{(2 k)}\left(x_{1}\right), \quad m=\{1,2, \ldots\}, \quad k=m-l, \\
+2(-1)^{k} \sum_{j=1}^{k} \frac{\left(i f\left(x_{1}\right)\right)^{k-j}}{(k-j) !}\left(i f^{\prime}\left(x_{1}\right)\right)^{j}\left(\Upsilon_{2(l)}^{(k)}\left(x_{1}\right)+2(-1)^{k}\left(x_{1}\right)\right)+
\end{array}\right]
$$


and $K_{1}=\varkappa_{1} /\left(r+\varkappa_{1}\right)+\varkappa_{2} /\left(1+r \varkappa_{2}\right), K_{2}=\varkappa_{1} /\left(r+\varkappa_{1}\right)-\varkappa_{2} /\left(1+r \varkappa_{2}\right), K_{3}=$ $1 /\left(\mu_{1}+\mu_{2} \varkappa_{1}\right)+\varkappa_{2} /\left(\mu_{2}+\mu_{1} \varkappa_{2}\right), K_{4}=1 /\left(\mu_{1}+\mu_{2} \varkappa_{1}\right)-\varkappa_{2} /\left(\mu_{2}+\mu_{1} \varkappa_{2}\right), r=\mu_{1} / \mu_{2}$.

In the case of zero-order approximation, $F_{0}=0$ and we arrive to the homogeneous equations (13), which have only trivial solution $\tau_{(0)}^{\prime}\left(x_{1}\right)=0$ corresponding to the problem of bimaterial with perfectly flat interface $\Gamma_{(0)}$ and piecewise uniform stress state:

$$
\begin{array}{r}
\Phi_{j(0)}(z)=\Upsilon_{j(0)}(z)=T_{j} / 4, \quad \tau_{(0)}\left(x_{1}\right)=\frac{M_{s}(\varkappa+1) T_{2}}{8 \mu_{2}}, \\
\sigma_{11(0)}(z)=T_{j}, T_{1}=\frac{\mu_{1}\left(\varkappa_{2}+1\right)}{\mu_{2}\left(\varkappa_{1}+1\right)} T_{2}, \quad z \in \Omega_{j}, \quad j=\{1,2\} .
\end{array}
$$

The nonhomogeneous equations (13), i. e. for $m>0$, are solved on the basis of the properties of Cauchy-type integrals letting to define the complex potentials $\Phi_{j(m)}$ and $\Upsilon_{j(m)}$. Taking into account the expression (8) and power series for complex potentials (9), we can write the following sequence:

$$
\begin{gathered}
\sigma_{n n(m)}(z)+i \sigma_{n t(m)}(z)=\Phi_{j(m)}(z)+\overline{\Phi_{j(m)}(z)}- \\
-\left(\Upsilon_{j(m)}(\bar{z})+\overline{\Phi_{j(m)}(z)}-(z-\bar{z}) \overline{\Phi_{j(n)}^{\prime}(z)}\right) e^{-2 i \alpha}, \\
\sigma_{t t(m)}(z)+\sigma_{n n(m)}(z)=4 \varepsilon \operatorname{Re} \Phi_{j(m)}(z), \quad z \in B_{j}, \quad m=0,1, \ldots, \quad j=\{1,2\} .
\end{gathered}
$$

And, finally, derive the expressions for stress tensor components in the terms of power series in small parameter $\varepsilon$ :

$$
\sigma_{n n}(z)=\sum_{m=0}^{\infty} \frac{\varepsilon^{m}}{m !} \sigma_{n n(m)}(z), \quad \sigma_{t t}(z)=\sum_{m=0}^{\infty} \frac{\varepsilon^{m}}{m !} \sigma_{t t(m)}(z), \quad \sigma_{n t}(z)=\sum_{m=0}^{\infty} \frac{\varepsilon^{m}}{m !} \sigma_{n t(m)}(z) .
$$

More detailed procedure of solving BVP (1)-(6) can be found in [40].

Numerical results. In order to verify the obtained solution, we use the finite element method (FEM) where the finite domain is considered employing the symmetry boundary conditions. The finite element model is schematically shown in Figure 2, $a$. The bulk phases are meshed with 6-node triangular elements for plane problems of linear elasticity. As it was mentioned above, the interface layer is considered as 1D domain with elastic properties that differ from the bulk ones. To model it in the framework of FEM formulation, we consider a 2-node truss element with unitary cross-section area $A$ and Young's modulus equal to $E_{t}=M_{s} / A$ [44]. The Figure 2, $b$ shows the refined mesh around the interface.

For the numerical calculations, we examine the stress concentration at the curved surface of aluminum substrate with Lamé constants equal to $\lambda_{2}=58.17 \mathrm{GPa}$ and $\mu_{2}=$ $26.13 \mathrm{GPa}$ covered by a coating with an arbitrary shear modulus $\mu_{1}$. For simplicity, the Poisson's ratios are assumed to be equal $\nu_{1}=\nu_{2}$. This assumption is often considered in metal-on-metal heteroepitaxial systems and allows to analyse the effect of the substrate through the only one parameter, coating-to-substrate stiffness ratio $r$. The interface effect is presented by the parameters $\lambda_{s}=6.851 \mathrm{~N} / \mathrm{m}, \mu_{s}=-0.376 \mathrm{~N} / \mathrm{m}[45]$.

The dependence of stress concentration coefficient on parameter $\varepsilon$ for different orders of approximate solution within BPM as well as calculated with FEM is plotted in Figure 3. 

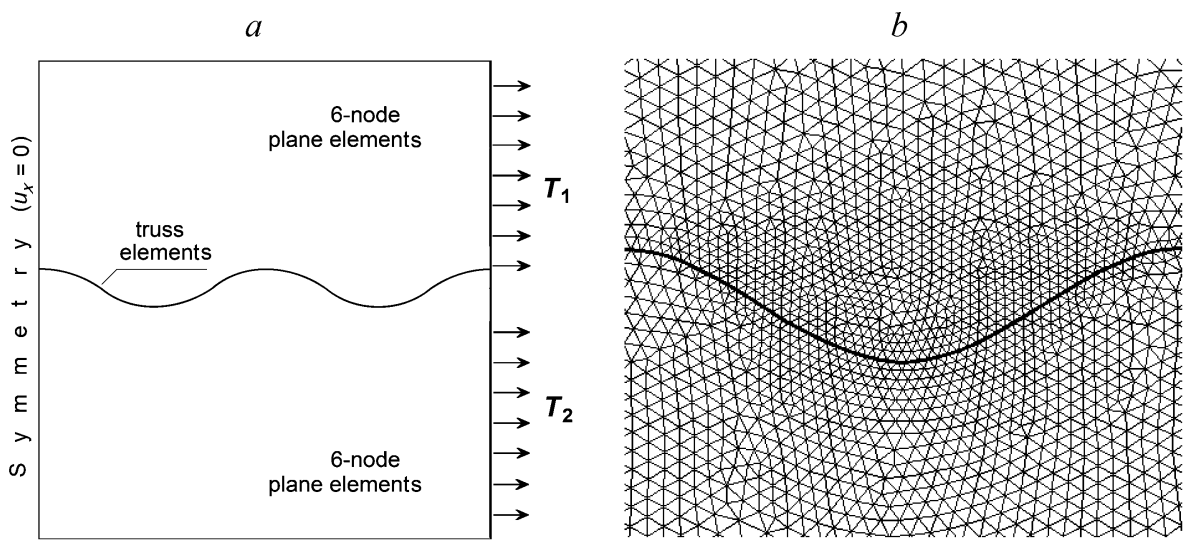

Fig. 2. Schematic diagram of finite element model (a) and the fragment of the bimaterial finite element model near the interface $(b)$

It shows that the accuracy of the linear BPM decreases with the increasing of amplitudeto-wavelength ratio $\varepsilon$, and we have to take into consideration high-order approximate solutions. For $a=20 \mathrm{~nm}, M_{s}=6.099 \mathrm{~nm}, r=0.1$ and $\varepsilon=0.1$, the relative difference between first- and second-order approximations is equal to $30 \%$. And the difference between fouth- and fifth-order approximations is equal to $2 \%$. The relative difference between FEM solution and fifth-order approximation for the same values of parameters is $15 \%$.

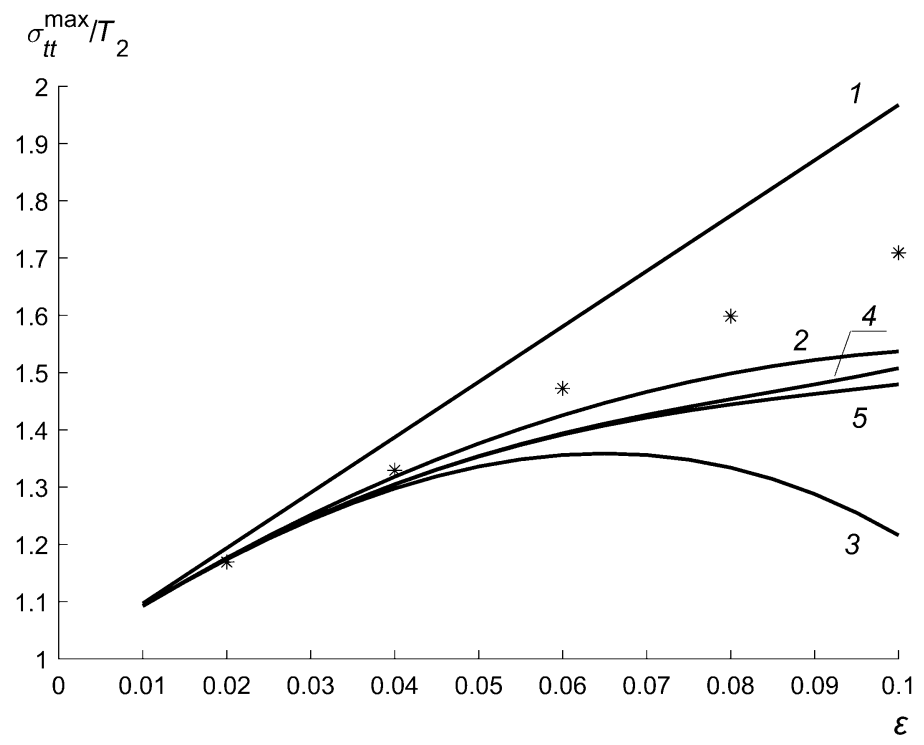

Fig. 3. The dependence of stress concentration coefficient on parameter $\varepsilon$ for $a=20 \mathrm{~nm}$, $M_{s}=6.099 \mathrm{~nm}$ and $r=0.1$

The stress $\sigma_{t t}$ is calculated in the bulk phase $B_{2}$. Solid lines $1-5$ corresponds to 1 st-5th-order approximations of BPM, respectively. FEM calculations are marked by asterisk. 
The variation of the stress concentration with the stiffness ratio $r$ is shown in Figure 4 in the case, when $M_{s}=6.099, a=20 \mathrm{~nm}$ and $\varepsilon=0.1$. One can see that the convergence rate of BPM solution increases with increasing of the stiffness ratio $r$. The relative difference between first- and second-order approximations is $20 \%$ and between fouth- and fifth-order approximations is $2 \%$ for $r=0.1$. For $r=0.9$ the consideration of nonlinear BPM terms does not have a significant effect on the solution: the relative difference between first- and second-order approximations is equal $3 \%$. When the stiffness ratio $r$ increase from 0.1 to 0.9 , the relative difference between FEM-solution and fifth-order approximations of BPM decrease from 14 to $3 \%$.

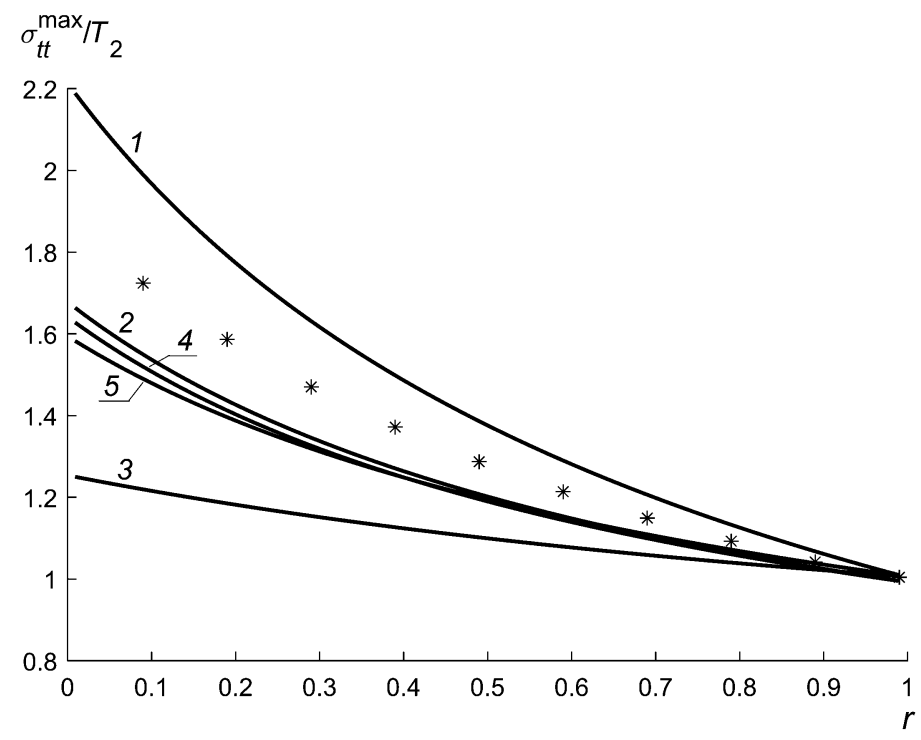

Fig. 4. The dependence of stress concentration coefficient on stiffness ratio $r$ for $a=20 \mathrm{~nm}, M_{s}=6.099 \mathrm{~nm}$ and $\varepsilon=0.1$

The stress $\sigma_{t t}$ is calculated in the bulk phase $B_{2}$. Solid lines $1-5$ corresponds to 1 st-5th-order approximations of BPM, respectively. FEM calculations are marked by asterisk.

Conclusion. In the present paper, we have studied the effect of nonlinear terms in the framework of boudary perturbation method solution on stress concentration near the nanopatterned bimaterial interface. Taking into account the plane strain conditions, the $2 \mathrm{D}$ boundary value problem was considered for the infinite two-component plane under uniaxial tension. Based on Gurtin-Murdoch surface/interface elasticity theory, the interface domain was modelled as a negligibly thin layer with the elastic properties differing from those of the bulk materials. Using specific approach developed in [40], we received semi-analytical solution taking into account non-linear approximations of boundary perturbation method. In order to verify the derived solution, the corresponding boundary value problem was solved by finite element method, where the interface layer was modelled by the truss elements. It was shown that the effect of the amplitude-towavelength ratio of surface undulation on the stress concentration is nonlinear. Also, we found that the convergence rate of the derived solution increases with the increasing of the stiffness ratio of bimaterial system and, vice versa, decreases with the increasing of the amplitude-to-wavelength ratio. 


\section{References}

1. Duan H. L., Weissmüller J., Wang Y. Instabilities of core-shell heterostructured cylinders due to diffusion and epitaxy: spheroidization and blossom of nanowires. Journal of the Mechanics and Physics of Solids, 2008, vol. 56, pp. 1831-1851.

2. Erdélyi Z., Beke D. L., Langer G. Interface kinetics and morphology on the nanoscale. Vacuum, 2010, vol. 84, pp. 26-31.

3. Romanova V. A., Balokhonov R. R. Numerical analysis of mesoscale surface roughening in a coated plate. Computational Materials Science, 2012, vol. 61, pp. 71-75.

4. Huang Y., Chen H., Wu J., Feng X. Controllable wrinkle configurations by soft micro-patterns to enhance the stretchability of Si ribbons. Soft Matter, 2014, vol. 10, pp. 2559-2566.

5. Kim H. K., Lee S. H., Yao Z., Wang C., Kim N. Y. Suppression of interface roughness between $\mathrm{BaTiO}_{3}$ film and substrate by $\mathrm{Si}_{3} \mathrm{~N}_{4}$ buffer layer regarding aerosol deposition process. Journal of Alloys and Compounds, 2015, vol. 653, pp. 69-76.

6. Bashkankova E. A., Vakaeva A. B., Grekov M. A. Perturbation method in the problem on a nearly circular hole in an elastic plane. Mechanics of Solids, 2015, vol. 50, pp. 198-207.

7. Gao H. A boundary perturbation analysis for elastic inclusions and interfaces. International Journal of Solids and Structures, 1991, vol. 28, pp. 703-725.

8. Gao H. Stress concentration at slightly undulating surfaces. Journal of the Mechanics and Physics of Solids, 1991, vol. 39, pp. 443-458.

9. Grekov M. A. The perturbation approach for a two-component composite with a slightly curved interface. Vestnik of Saint Petersburg University. Series 1. Mathematics. Mechanics. Astronomy, 2004, iss. 1, pp. 81-88. (In Russian)

10. Grekov M. A., Kostyrko S. A. A film coating on a rough surface of an elastic body. Journal of Applied Mathematics and Mechanics, 2013, vol. 77, N 1, pp. 79-90.

11. Grekov M. A., Kostyrko S. A. A multilayer film coating with slightly curved boundary. International Journal of Engineering Science, 2015, vol. 89, pp. 61-74.

12. Kainuma S., Jeong Y. S., Ahn J. H. Investigation on the stress concentration effect at the corroded surface achieved by atmospheric exposure test. Materials Science and Engineering, A, 2014, vol. 602, pp. 89-97.

13. Medina H. A stress-concentration-formula generating equation for arbitrary shallow surfaces. International Journal of Solids and Structures, 2015, pp. 86-93.

14. Vikulina Y. I., Grekov M. A., Kostyrko S. A. Model of film coating with weakly curved surface. Mechanics of Solids, 2010, vol. 45, pp. 778-788.

15. Cammarata R. C., Sieradzki K. Effects of surface stress on the elastic moduli of thin films and superlattices. Physical Review Letters, 1989, vol. 62, pp. 2005-2008.

16. Fartash A., Fullerton E. E., Schuller I. K. Evidence for the supermodulus effect and enhanced hardness in metallic superlattices. Physical Review, B, Condensed Matter, 1991, vol. 44, pp. 13760-13763.

17. Sun C.T., Zhang H. T. Size-dependent elastic moduli of platelike nanomaterials. Journal of Applied Physics, 2003, vol. 93, pp. 1212-1218.

18. Gurtin M. E., Murdoch A. I. A continuum theory of elastic material surfaces. Archive for Rational Mechanics and Analysis, 1975, vol. 57, pp. 291-323.

19. Gurtin M.E., Murdoch A.I. Surface stress in solids. International Journal of Solids and Structures, 1978, vol. 14, pp. 431-440.

20. Goldstein R. V., Gorodtsov V. A., Ustinov K. V. Effect of residual stress and surface elasticity on deformation of nanometer spherical inclusions in an elastic matrix. Physical Mesomechanics, 2010, vol. 13, pp. 318-328.

21. Altenbach H., Eremeyev V.A., Morozov N.F. Surface viscoelasticity and effective properties of thin-walled structures at the nanoscale. International Journal of Engineering Science, 2012, vol. 53, pp. 83-89.

22. Eremeyev V.A. On effective properties of materials at the nano- and microscales considering surface effect. Acta Mechanica, 2016, vol. 227(1), pp. 29-42.

23. Dai M., Li M., Schiavone P. Plane deformations of an inhomogeneity - matrix system incorporating a compressible liquid inhomogeneity and complete Gurtin-Murdoch interface model. Journal of Applied Mechanics, 2018, vol. 85, p. 121010.

24. Dai M., Wang Y. J., Schiavone P. Integral-type stress boundary condition in the complete GurtinMurdoch surface model with accompanying complex variable representation. Journal of Elasticity, 2019, vol. 134 , pp. $235-241$.

25. Iovane G., Nasedkin A. V. Numerical modelling of two-phase piezocomposites with interface mechanical anisotropic effects. Advanced Structured Materials, 2019, vol. 103, pp. 293-304.

26. Song K., Song H. P., Schiavone P., Gao C.F. The effects of surface elasticity on the thermal 
stress around a circular nano-hole in a thermoelectric material. Mathematics and Mechanics of Solids, 2019, vol. 24(10), pp. 3156-3166.

27. Nazarenko L., Bargmann S., Stolarski H. Closed-form formulas for the effective properties of random particulate nanocomposites with complete Gurtin-Murdoch model of material surfaces. Continuum Mechanics and Thermodynamics, 2017, vol. 29, pp. 77-96.

28. Nazarenko L., Stolarski H., Altenbach H. Effective properties of short-fiber composites with Gurtin-Murdoch model of interphase. International Journal of Solids and Structures, 2016, vol. 97, pp. $75-88$.

29. Altenbach H., Eremeyev V. A., Lebedev L. P. On the existence of solution in the linear elasticity with surface stresses. ZAMM Journal of Applied Mathematics and Mechanics: Zeitschrift fur angewandte Mathematik und Mechanik, 2010, vol. 90, pp. 231-240.

30. Steigmann D.J., Ogden R.W. Plane deformations of elastic solids with intrinsic boundary elasticity. Proceedings of the Royal Society, A, 1997, vol. 453, pp. 853-877.

31. Steigmann D. J., Ogden R. W. Elastic surface-substrate interactions. Proceedings of the Royal Society, A, 1997, vol. 455, pp. 437-474.

32. Zemlyanova A. Y., Mogilevskaya S. G. Circular inhomogeneity with Steigmann-Ogden interface: local fields, neutrality, and maxwell's type approximation formula. International Journal of Solids and Structures, 2018, vol. 135, pp. 85-98.

33. Zemlyanova A.Y., Mogilevskaya S. G. On spherical inhomogeneity with Steigmann-Ogden interface. Journal of Applied Mechanics, 2018, vol. 85, p. 121009.

34. Benveniste Y., Miloh T. Imperfect soft and stiff interfaces in two-dimensional elasticity. Mechanics of Materials, 2001, vol. 33, pp. 309-323.

35. Lurie S., Belov P. Gradient effects in fracture mechanics for nano-structured materials. Engineering Fracture Mechanics, 2014, vol. 130, pp. 3-11.

36. Mohammadi P., Liu L. P., Sharma P., Kukta R. V. Surface energy, elasticity and the homogenization of rough surfaces. Journal of the Mechanics and Physics of Solids, 2013, vol. 61, pp. 325340 .

37. Wang Y., Weissmüller J., Duan H. L. Mechanics of corrugated surfaces. Journal of the Mechanics and Physics of Solids, 2010, vol. 58, pp. 1552-1566.

38. Weissmüller J., Duan H.L. Cantilever bending with rough surfaces. Physical Review Letters, 2008, vol. 101, p. 146102 .

39. Grekov M. A., Kostyrko S. A. Surface effects in an elastic solid with nanosized surface asperities. International Journal of Solids and Structures, 2016, vol. 96, pp. 153-161.

40. Kostyrko S. A., Grekov M. A. Elastic field at a rugous interface of a bimaterial with surface effects. Engineering Fracture Mechanics, 2019, vol. 216, p. 106507.

41. Kostyrko S. A., Grekov M. A., Altenbach H. Stress concentration analysis of nanosized thin-film coating with rough interface. Continuum Mechanics and Thermodynamics, 2019, vol. 31, pp. 1863-1871.

42. Vakaeva A. B., Shuvalov G. M., Kostyrko S. A. Interfacial stresses in bimaterial composites with nanosized interface relief. Proceedings of the 8th International Conference on Coupled Problems in Science and Engineering. Coupled Problems, 2019, pp. 679-688.

43. Vikulina Y.I., Grekov M. A. The stress state of planar surface of a nanometer-sized elastic body under periodic loading. Vestnik of Saint Petersburg University. Mathematics, 2012, vol. 45, pp. 174-180.

44. Tian L., Rajapakse R. K. N. D. Finite element modeling of nanoscale inhomogeneities in an elastic matrix. Computational Materials Science, 2007, vol. 41, pp. 44-53.

45. Miller R.E., Shenoy V.B. Size-dependent elastic properties of nanosized structural elements. Nanotechnology, 2000, vol. 11, pp. 139-147.

Received: April 27, 2020.

Accepted: May 28, 2020.

Authors' information:

Gleb M. Shuvalov - Postgraduate Student, Assistant; g.shuvalov@spbu.ru

Alexandra B. Vakaeva - PhD in Physics and Mathematics, Senior Lecturer; a.vakaeva@spbu.ru

Denis A. Shamsutdinov - Master Student; st070089@student.spbu.ru

Sergey A. Kostyrko - PhD in Physics and Mathematics, Associate Professor; s.kostyrko@spbu.ru 


\title{
Влияние нелинейных слагаемых метода возмущений на концентрацию напряжений вблизи наноструктурированной межфазной границы биматериала*
}

\author{
Г. М. Шувалов, А. Б. Вакаева, Д. А. Шамсутдинов, С. А. Костырко \\ Санкт-Петербургский государственный университет, Российская Федерация, \\ 199034, Санкт-Петербург, Университетская наб., 7-9
}

Для цитирования: Shuvalov G. M., Vakaeva A. B., Shamsutdinov D. A., Kostyrko S. A. The effect of nonlinear terms in boundary perturbation method on stress concentration near the nanopatterned bimaterial interface // Вестник Санкт-Петербургского университета. Прикладная математика. Информатика. Процессы управления. 2020. Т. 16. Вып. 2. С. 165-176. https://doi.org/10.21638/11701/spbu10.2020.208

В работе исследовано влияние нелинейных слагаемых метода возмущений на концентрацию напряжений вблизи криволинейной межфазной границы биматериала под действием одноосной нагрузки. Предполагается, что упругие свойства межфазной границы и основных материалов отличаются друг от друга. С использованием теории поверхностной упругости Гёртина-Мёрдока, метода возмущений и соотношений Мусхелишвили решение задачи представлено в виде степенного ряда относительно коэффициентов разложения напряжения по степеням малого параметра. Для верификации полученного решения применялся метод конечных элементов. Было показано, что даже при малых значениях отношения амплитуды к длине волны искривления межфазной границы учет нелинейных слагаемых метода возмущений существенно влияет на решение. Также обнаружено, что скорость сходимости полученного решения повышается с ростом коэффициента относительной жесткости системы и, наоборот, уменьшается с увеличением отношения амплитуды к длине волны.

Ключевые слова: наноматериалы, межфазное напряжение, плоская задача теории упругости, метод возмущений, метод конечных элементов.

Контактная информация:

Шувалов Глеб Михайлович - аспирант, ассистент; g.shuvalov@spbu.ru

Вакаева Александра Борисовна - канд. физ.-мат. наук, ст. преподаватель; a.vakaeva@spbu.ru

Шамсутдинов Денис Алексеевич - магистрант; st070089@student.spbu.ru

Костырко Сергей Алексеевич - канд. физ.-мат. наук, доц.; s.kostyrko@spbu.ru 00062).

* Работа выполнена при финансовой поддержке Российского научного фонда (проект № 19-71- 